\title{
A SEMANA CULTURAL NO COLÉGIO ESTADUAL GELVIRA CORRÊA PACHECO: UMA POSSIBILIDADE DE EDUCAÇÃO PARA O LAZER
}

\author{
CULTURAL WEEK AT THE GELVIRA CORRÊA PACHECO STATE SCHOOL: A LEISURE \\ EDUCATION POSSIBILTY
}

\author{
Felipe Sobczynski Gonçalves ${ }^{1}$ \\ Rodrigo de França ${ }^{2}$ \\ Simone Rechia ${ }^{3}$
}

\section{Resumo}

Com a percepção da necessidade de se criar um ambiente de discussão e reflexão com os alunos, em torno da temática do espaço escolar e seu entorno, emergiu o seguinte desafio: como a Educação Física Escolar pode contribuir para o fortalecimento da identidade local, sem deixar de lado sua especificidade? Apoiados na abordagem qualitativa, as etapas de investigação foram: seleção da temática, aplicação de roteiro de observação e questionários avaliativos. Este artigo tematiza o projeto da Semana Cultural desenvolvido no Colégio Estadual Gelvira Corrêa Pacheco, em Curitiba/PR. Para concretização da proposta - que tinha como temática "O Bairro da nossa Escola" - também foi necessário buscar relações interdisciplinares dentro do espaço escolar. Nossa preocupação foi trazer algo que pudesse contribuir à formação dos educandos e que, de alguma forma, levasse em consideração sua realidade e tivesse relevância para o seu dia-a-dia, fomentando uma educação para o lazer, na qual o corpo discente seja instrumentalizado para assumir o protagonismo das suas escolhas, no seu tempo/espaço destinado às vivências de lazer.

Palavras-chave: lazer; educação; semana cultural

Abstract

By the requirement to create a discussion and thought environment with the students, around the school space and its surroundings, the following challenge has emerged: how the Physical Education can afford the enhancement of local identity, without disregard it particularity? Based on qualitative approach, research stages were: theme selection, application of observation guidelines and evaluative questionnaire. This study aims to focus the Cultural Week project developed at the State School Gelvira Corrêa Pacheco of Curitiba/PR, Brazil. To realize the proposition - at the name of "Our School Neighborhood" - was also necessary to looking for an interdisciplinary path in school. Our purpose was to bring something that could contribute for the growth of the students, considering somehow their reality, which had significance on day-by-day, building up a leisure education, whom provide to the student body be the leading figure of their choices, about the leisure time and space.

Keywords: leisure; education; cultural week

Fecha de recepción: 20 de octubre de 2015

Fecha de aprobación: 10 de marzo de 2016

Para citar este artículo:

Sobczynski Gonçalves, F., De França, R. y Rechia, S. (2016). A semana cultural no colégio estadual Gelvira Corrêa Pacheco: uma possibilidade de educação para o lazer. Lúdica Pedagógica, (23), 63-70.

1 Doutorando do Programa de Pós-graduação em Educação Física da Universidade Federal do Paraná. Mestre em Educação Física pela Universidade Federal do Paraná (2008). Especialista em Educação Física Escolar pela Universidade Federal do Paraná (2005). Licenciado em Educação Física pela Universidade Federal do Paraná (2003). Pesquisador do Grupo de Estudos e Pesquisa em Lazer, Espaço e Cidade - GEPLEC/UFPR. Correo electrónico: felipesgon@gmail.com

2 Mestre em Educação Física pela Universidade Federal do Paraná (2007). Licenciado em Educação Física pela Universidade Federal do Paraná (2004). Pesquisador do Grupo de Estudos e Pesquisa em Lazer, Espaço e Cidade - GEPLEC/UFPR. Correo electrónico: rodrigofranca@yahoo.com.br

3 Pós Doutorado pelo Instituto Nacional de Educação Física da Catalunha (Barcelona/Espanha 2009). Doutorado em Educação Física pela Universidade Estadual de Campinas (2003). Mestrado em Educação pela Pontifícia Universidade Católica do Paraná (1998). Licenciada em Educação Física pela Pontifícia Universidade Católica do Paraná (1986). Correo electrónico: simone@ufpr.br 


\section{INTRODUÇÃO}

0 presente trabalho procura apresentar a síntese de uma pesquisa realizada a partir do desenvolvimento da Semana Cultural que se efetivou no Colégio Estadual Gelvira Corrêa Pacheco ${ }^{4}$. Nossa preocupação ao efetivar essa semana no interior da disciplina de Educação Física era levar em consideração tudo o que estava presente em nosso planejamento bimestral, além dos documentos oficiais, tais como o Projeto Político Pedagógico da Escola, a Proposta Pedagógica Curricular e as Diretrizes Curriculares da Educação Básica.

Diante disso, para concretizarmos tal proposta - que tinha como temática "O Bairro ${ }^{5}$ da nossa Escola" — também foi necessário buscar relações com as diferentes áreas do conhecimento dentro do espaço escolar. Ao ponderarmos a respeito desse projeto, tivemos como objetivos: reconhecer os diferentes espaços e equipamentos de lazer do bairro, tendo a preocupação de mapear a realidade do mesmo e como os alunos e as alunas se apropriam destes; promover uma educação para o lazer, na qual o corpo discente possa ser instrumentalizado para assumir o protagonismo no seu tempo/espaço destinado às vivências de lazer; reforçar a importância do diálogo com as outras disciplinas ao trabalhar com conceitos multifacetados.

Com a percepção da necessidade de se criar um espaço de discussão e reflexão dentro da escola, em torno da temática do bairro, emergiu o seguinte desafio: como a Educação Física Escolar pode fazer parte de tal projeto sem deixar de lado sua especificidade?

Defendemos que este trabalho se justifica pela necessidade de se valorizar a disciplina de Educação Física por meio de conhecimentos que podem e devem estar presentes em outras áreas do conhecimento. Dentre as possibilidades, encontra-se o lazer, que se destaca por ser um campo multidisciplinar e que permite a práxis de profissionais que atuam nas diversas áreas, dentre as quais destacam-se a Educação Física, Turismo, Hotelaria, Geografia, Sociologia, Meio Ambiente, Terapia Ocupacional, entre outras.

4 Trata-se de uma unidade educacional pertencente à Rede Estadual de Educação do Paraná, na cidade de Curitiba.

5 A escola se localiza no Bairro Barreirinha, o qual fica na região Norte da cidade, apresentando atualmente uma população de 18.017 habitantes.
Essa multiplicidade de formações mostra que é possível qualificar a atuação nessa esfera, no entanto é preciso que o profissional tenha uma instrução que não se resuma simplesmente à prática de atividades, mas que consiga refletir teoricamente a respeito de sua atuação. Nessa perspectiva, o lazer como um campo que abrange diferentes áreas favorece o desenvolvimento de propostas interdisciplinares.

A interdisciplinaridade é o método de pesquisa e de ensino suscetível de se fazer com que duas ou mais disciplinas interajam entre si. Interação esta que pode ir da simples comunicação das ideias até a integração mútua dos conceitos, da epistemologia, da terminologia, da metodologia, dos procedimentos, dos dados e da organização da pesquisa (Japiassu \& Marcondes, 1991). Em outras palavras, a interdisciplinaridade se manifesta quando determinada disciplina se utiliza de conceitos, teorias ou práticas de outra área do conhecimento para auxiliar na compreensão de seu conteúdo. Para que, de fato, isso aconteça é preciso superar a visão fragmentada do conhecimento, o que conduz ao entendimento de que para se trabalhar com determinado objeto de estudo devemos procurar também em outras áreas do conhecimento os devidos referenciais teóricos que permitam uma abordagem mais ampla desse objeto.

Procurando dar visibilidade e problematizar as questões presentes no dia-a-dia da escola, a partir das intervenções propostas, optamos pelo método de pesquisa qualitativa, considerando a prática social trazida pelos alunos e alunas, sem deixar de relacionar o conhecimento que foi produzido historicamente e sistematizado socialmente. Os alunos e as alunas apresentam, inicialmente, uma visão sincrética da realidade e nessa perspectiva procuramos desenvolver ações que dessem condições de atingir uma visão sintética. Nesse processo de ensino-aprendizagem, ambos, professor e aluno, transformam-se mutuamente. (Saviani, 2002).

Com a preocupação de construirmos uma estrutura coerente e articulada para a elaboração deste texto, buscamos: apresentar o conceito de lazer que fundamentou o desenvolvimento do trabalho; no percurso metodológico apresentamos os procedimentos de pesquisa e a maneira como encaminhamos as análises e reflexões da semana cultural; na discussão dos resultados são abordadas algumas questões identificadas no desenvolvimento do evento em conjunto com as considerações finais quando apontamos algumas questões que nos 
fazem ponderar a respeito da possibilidade de desenvolver um processo de transformação e emancipação dos sujeitos por meio da educação para o lazer.

\section{O LAZER}

A dimensão conceitual do lazer que debatemos com os alunos e as alunas nesse processo se pautou pelo desenvolvido por Mascarenhas (2003), que o apresenta como um "fenômeno tipicamente moderno, resultante das tensões entre capital e trabalho, que se materializa como um tempo e espaço de vivências lúdicas, sendo um lugar de organização da cultura, perpassado por relações de hegemonia" (p. 97). As referidas tensões, portanto, parecem ter delineado a gênese do lazer. Nas palavras do autor:

0 chamado tempo livre surge em meio às contradições do próprio desenvolvimento capitalista como conquista de classe... a noção de tempo livre e o próprio entendimento de lazer não surgem com a Revolução Industrial, mas em outro cenário, quando as lutas sociais conseguem impor poucas, mas significativas transformações sociais. (Mascarenhas, 2000, p.77).

Podemos observar que é a partir dos sucessivos esforços e organização coletiva dos trabalhadores, voltados para equalizar, ou melhor, diminuir as desigualdades na esfera do trabalho, que podemos intentar o aumento de um importante "tempo livre" para o desenvolvimento de outras atividades, bem como dos próprios indivíduos e suas coletividades.

Mascarenhas (2005) esclarece que o lazer constitui-se como um tempo e espaço de organização da cultura, ampliando as oportunidades para que se questionem os valores da ordem social vigente, de forma que as pessoas possam se apropriar, reelaborar e produzir cultura.

Nessa esteira de discussão, a cultura é perpassada por relações de predominância, ou seja, torna-se palco social de disputa hegemônica, onde a tensão se dá entre a penetração massiva da Indústria Cultural no mercado da diversão do entretenimento, ou seja, no "mercolazer"6 e a ação política e pedagogicamente orientada para uma formação crítica e criativa.

6 "Dinâmica tendencial de mercantilização do lazer em sua manifestação mais imediata, quando assume a forma de mercadoria propriamente dita" (Mascarenhas, 2005, p. 156).
Podemos afirmar que esse conceito permitiu que os alunos e as alunas compreendessem a possibilidade do duplo processo educativo do lazer, ou seja, uma educação para e pelo lazer. Nesta distinção, largamente explorada por alguns autores, Requixa (1977); Parker (1978); Dumazedier (1980); Camargo (1998); Marcellino $(1998,2002 a, 2002 b)$, todos corroboram com o preceito de que o lazer pode ser tanto um objeto de reflexão e ensino - educação para o lazer — ou seja, conteúdo específico a ser apropriado e entendido enquanto direito constitucional, para potencializar as próprias escolhas, espaços, práticas e atitudes no tempo e espaço disponíveis. Para Camargo (1998),

Não se trata de diminuir a importância da educação para o trabalho... Nem por isso, contudo, deve-se esquecer da importância de uma educação para o lúdico, para o desfrute das horas que, sem dúvida, vão-se poder dedicar ao lazer, sem o qual a vida - assentada apenas no trabalho - será aborrecida e pobre, e a aposentadoria será simbólica e não raro, literalmente a morte. (p. 12).

Bem como um difusor, uma ferramenta de ensino - educação pelo lazer - pois por meio de vivências significativas no âmbito do lazer, os sujeitos podem vislumbrar a oportunidade de crescer e se desenvolver pessoal e socialmente.

Diante desse entendimento do potencial educativo das vivências lúdicas, experienciadas no tempo/espaço disponíveis, ficou evidente a oportunidade de conduzir um projeto que transcendesse aos muros da escola e vislumbrasse uma ressignificação sociocultural. Para Marcellino (1998), "só tem sentido falar em aspectos educativos do lazer, se esse for considerado... como um dos possíveis canais de atuação no plano cultural, tendo em vista contribuir para uma nova ordem moral e intelectual, favorecedora de mudanças no plano social" (p. 63).

Trabalhar com o significado do lazer dentro das aulas de Educação Física na escola regular é um desafio, principalmente pela dificuldade que os alunos e alunas têm para compreender o conceito. No entanto, mesmo sabendo de sua complexidade, não podemos deixar de trabalhá-lo, principalmente por ser um conhecimento desenvolvido socialmente e que os alunos e alunas têm direito ao acesso. 
Dentro dos documentos oficiais da Secretaria de Estado da Educação do Paraná, mais especificamente no interior das Diretrizes Curriculares, o lazer é considerado um Elemento Articulador ${ }^{7}$. Recebe esse nome pelo fato de integrar e interligar as práticas corporais de forma mais reflexiva e contextualizada, isso quer dizer que o lazer pode ser desenvolvido dentro de todos os conteúdos da Educação Física escolar, seja por meio do Esporte, da Ginástica, da Dança, das Lutas e dos Jogos e Brincadeiras. Assim, o lazer como um elemento articulador não pode ser entendido como conteúdo paralelo, nem tampouco trabalhado apenas teoricamente e/ou de maneira isolada.

\section{O CAMINHO PERCORRIDO}

Trata-se de uma pesquisa qualitativa que busca associar conceitos e noções complementares e concorrentes, procurando entender seus diferentes níveis de desenvolvimento teórico e prático no interior das áreas disciplinares.

Dentre as antinomias relevantes, se encontram as relações entre o universal e o particular; entre o global e o local; entre o micro e o macro; entre o coletivo e o individual; entre o todo e as partes; entre a análise e a síntese; entre as relações cêntricas, acêntricas e policêntricas". (Minayo, Assis \& Souza, 2005, p.34).

Essa forma de abordagem, segundo a autora, atua levando em consideração a compreensão, a inteligibilidade dos fenômenos sociais e o seu significado, além da intencionalidade que lhe atribuem os sujeitos.

Em uma investigação avaliativa por métodos qualitativos trabalha-se com atitudes, crenças, comportamentos e ações, procurando-se entender a forma como as pessoas interpretam e conferem sentido a suas experiências e ao mundo em que vivem... Neste tipo de investigação acredita-se que exista uma relação dinâmica e inseparável entre o mundo real e a subjetividade dos participantes. (Minayo et al., 2005, p.82).

7 "A proposta dos Elementos Articuladores se aproxima daquilo que Pistrak (2000) denomina por Sistema de Complexos Temáticos, isto é, aquilo que permite ampliar o conhecimento da realidade estabelecendo relações e nexos entre os fenômenos sociais e culturais". (Paraná, 2008, p.53).
Esta pesquisa buscou ler e apresentar a realidade com a preocupação de trazer à reflexão um determinado fenômeno social. Em tal caso, como os alunos e alunas percebem o conceito lazer e quais espaços do bairro estão disponíveis para que toda a comunidade usufrua neste tempo e espaço. Podemos então afirmar que se trata de uma investigação social que, segundo Minayo (2000), considera o sujeito do estudo "...pertencente a determinado grupo social ou classe com suas crenças, valores e significados" (p.22). Posto isto, nos pautamos numa abordagem qualitativa, fundamentalmente empírica. É possível afirmar que nesse tipo de pesquisa a descrição e o esforço intelectual são indispensáveis na tentativa de interpretar códigos, entender as estruturas e significações.

Portanto, para efetivarmos esse trabalho, as etapas de investigação foram: seleção da temática, aplicação de roteiro de observação e questionários avaliativos. Como estratégia metodológica para a coleta de dados a partir do desenvolvimento das aulas, nos apropriamos dos pressupostos da Pedagogia Histórico-Crítica ${ }^{8}$, desenvolvida por Demerval Saviani (2002). Para o autor, tal proposta emerge das necessidades existentes na prática pedagógica de muitos educadores e educadoras, pois as pedagogias tradicionais, nova e tecnicista, não apresentavam a historicidade como característica fundamental, deixando de lado ou em segundo plano a consciência dos condicionantes histórico-sociais da educação.

\section{A SEMANA CULTURAL}

0 primeiro passo realizado pela escola para efetivar a realização da Semana Cultural, desenvolvida entre os dias 28 de outubro a 01 de novembro de 2013, foi uma reunião pedagógica, na qual todos os professores e professoras participaram levantando a temática a ser desenvolvida, e ficou definido que todas as disciplinas trabalhariam com autores e autoras que apresentassem relevância teórica e cultural para a realidade escolar ${ }^{9}$.

8 No desenvolvimento das aulas utilizamos a sequência pedagógica proposta pelo autor: Prática Social, Problematização, Instrumentalização, Catarse e Nova Prática Social (Saviani, 2002).

9 Os autores que deveriam ser levados em consideração foram: Ensino Médio ( $1^{\circ}$ e $2^{\circ}$ anos) o geógrafo Milton Santos e $9^{\circ}$ Anos o poeta e compositor Vinícius de Moraes (pelo fato de ser o ano de comemoração do centenário de seu nascimento 19/10/1913), além do escritor, poeta, crítico literário e tradutor curitibano Paulo Leminski. 
Dentre as atividades que as turmas deveriam realizar, destacam-se a montagem e apresentação de um painel a respeito do autor ou autora, enfatizando sua formação acadêmica e principais obras literárias; caracterizar um(a) estudante da turma como o autor ou autora escolhido(a); elaborar uma paródia a respeito do(a) mesmo(a); responder a 10 questões relacionadas ao tema, além da proposição de algumas atividades lúdicas, procurando integrar professores, professoras, alunos e alunas.

Para as turmas que trabalhávamos (Ensino Médio), foi definido que o autor estudado seria o Geógrafo Milton Santos (autor negro), com grande prestígio no exterior, mas pouco valorizado no Brasil. Diante disso, cada disciplina deveria trazer para a sua realidade possíveis reflexões, partindo dos conceitos trabalhados pelo autor.

Na Educação Física, procuramos trabalhar os espaços e equipamentos de lazer do bairro, norteados pela pedagogia Histórico-Crítica, iniciando a prática social com a seguinte questão: Para você o que é lazer? Na sequência levantamos as seguintes problematizações: Como você aproveita seu tempo de lazer? Você tem algum grupo que se reúne para jogar bola, dançar, andar de bicicleta, conversar, passear? Você prefere ler ou ver televisão nos momentos de lazer? Vocêjá se preocupou com o seu tempo de lazer? Você vai ao cinema, teatro, museu? Tem acesso a essas opções? O trabalho pode ser considerado lazer? Tudo o que observamos ou fazemos no tempo livre élazer? Futebol é lazer? E cozinhar?

Posteriormente, como instrumentalização, apresentamos o supracitado conceito de lazer proposto por Mascarenhas (2003) e fizemos um debate, no qual os alunos deveriam responder as questões da problematização. Na sequência, foi realizada pelos estudantes e pelas estudantes, a pesquisa de campo, na qual utilizaram um roteiro de observação $0^{10}$ dos espaços e equipamentos de lazer presentes no bairro.

Para finalizar a semana cultural, como momento de catarse $^{11}$, foi definida a realização de um "caça ao tesouro" que teve como temática o bairro em que a

10 O roteiro de observação utilizado foi adaptado do roteiro criado e validado pelo GEPLEC (Grupo de Estudos e Pesquisa em Lazer, Espaço e Cidade) da UFPR.

11 Termo aqui emprestado da pedagogia Histórico-Crítica, correspondente à etapa dialética de assimilação e síntese dos conteúdos (Gasparin, 2002). escola está localizada. 0 objetivo final dessa atividade foi fazer com que cada turma recebesse uma peça do quebra-cabeça e conseguisse montar o mapa do bairro. Como forma de avaliação do processo, elaboramos um questionário que deveria ser respondido por todos os alunos e alunas.

Dentro dessa temática, buscando trabalhar de maneira interdisciplinar, trouxemos à Educação Física os conceitos do geógrafo Milton Santos que contribuíssem no entendimento da apropriação dos espaços de lazer. Acerca dos conceitos trabalhados, destacamos o conceito de Espaço discutido pelo autor. Para Santos (1986),

O espaço não é um pano de fundo impassível e neutro. Assim, este não é apenas um reflexo da sociedade nem um fato social apenas, mas um condicionante condicionado, tal como as demais estruturas sociais. 0 espaço é uma estrutura social dotada de um dinamismo próprio e revestido de uma certa autonomia, na medida em que sua evolução se faz segundo leis que lhe são próprias. Existe uma dialética entre forma e conteúdo, que é responsável pela própria evolução do espaço. (p.15).

Diante disso é possível afirmar a materialização da interdisciplinaridade proposta, a partir da apropriação da Educação Física de um caro conceito da Geografia para potencializar a compreensão do seu próprio conteúdo. No caso desse projeto, a preocupação era fazer com que os alunos e alunas tivessem acesso ao conceito mais aprofundado de espaço para que, na sequência, pudessem realizar uma pesquisa de campo no seu espaço cotidiano, seja ele uma praça ou algum parque que fizesse parte do bairro, no qual a escola está inserida.

\section{RESULTADOS (NÃO FINAIS)}

Buscando finalizar nossas reflexões, utilizamos essa terminologia "resultados (não finais)" por acreditarmos que o pesquisador e pesquisadora devem buscar a formação crítica em seus alunos e alunas pois, "a ciência é apenas uma forma de expressão desta busca, não exclusiva, não conclusiva, não definitiva" (Minayo, 1994, p. 10).

Ao entendermos a realidade como sendo dialética, buscamos aqui, apresentar de forma não conclusiva os resultados obtidos durante o processo de avaliação. 
Entendendo-a de forma contínua, permanente, cumulativa, a qual segundo Luckesi (1986), é "dimensionada por um modelo teórico de mundo e de educação traduzida em prática pedagógica" (p.27), que na Educação Física assume uma concepção de linguagem corporal.

Antes de iniciarmos a discussão dos resultados, sentimos a necessidade de esclarecer que nossa preocupação não foi levantar dados ou elementos que quantificassem nosso projeto. Por se tratar de uma pesquisa de caráter qualitativo, focada na dimensão atitudinal, buscamos compreender a maneira como os discentes interpretam e conferem sentido às suas experiências, seja na escola ou fora dela.

Nesse sentido, podemos afirmar que o projeto desenvolvido no Colégio Estadual Gelvira Corrêa Pacheco atingiu seus objetivos, primeiramente pela efetiva participação dos alunos e alunas em todas as atividades propostas. Os dados coletados e exibidos, por meio dos relatórios de observação e posteriormente pelas apresentações dos mesmos, também permitem afirmarmos que os objetivos foram alcançados. A partir das exposições e dos relatos realizados em sala de aula fica evidente a escassa participação dos discentes e da comunidade em geral no cuidado com aquilo que é público, além de um distanciamento da gestão pública no que se refere a manutenção e a segurança dos espaços e equipamentos de lazer do bairro.

Algo interessante de percebermos com as apresentações dos resultados das observações, realizadas pelos alunos e alunas da escola, é que apesar de ainda estarem nos primeiros anos do Ensino Médio, deram conta de apresentar para o debate e reflexão - em um nível menor de complexidade - alguns dados que autores e autoras da área, especialmente os estudantes e as estudantes em nível de graduação e pós-graduação que participam do GEPLEC, vêm apresentando em suas pesquisas.

Como os próprios alunos e alunas relataram em suas apresentações, os espaços tendem a ficar vazios pela falta de segurança e manutenção. Um exemplo recorrente, a esse respeito, presente nas falas é o Parque da Barreirinha, criado em 1959 e que apresenta uma grande área coberta por matas nativas e lagos, além de equipamentos como churrasqueiras, playground, biblioteca, ciclovia, quadras de futebol de areia e vôlei.
Para que de fato ocorra apropriação por parte da comunidade é preciso que, além da manutenção dos mesmos, exista segurança. Não se trata apenas de uma segurança policial - o que pode colaborar — porém Jacobs (2003), fala da existência de algumas características, dentre elas a de que "devem existir olhos para as ruas, os olhos daqueles que podemos chamar de proprietários naturais da rua" (p.36). Para a autora, "a segurança das ruas é mais eficaz, mais informal e envolve menos traços de hostilidade e desconfiança exatamente quando as pessoas as utilizam e usufruem espontaneamente e estão menos conscientes, de que estão policiando" (p.37).

Nesse sentido, entendemos que deve haver uma ação compartilhada entre o poder público e a comunidade, ou seja, é preciso pensar em projetos e programas diferenciados para que todos e todas possam, de fato, se apropriar desses espaços e equipamentos no tempo e espaço de lazer. Uma estratégia pode ser o desenvolvimento de políticas públicas e uma efetiva participação da comunidade, organizada nas diversas formas de ativismos sociais, questionando, reivindicando e atuando para que os mesmos tenham constante manutenção, melhoria e sejam mais seguros.

Por meio dessas reflexões, podemos afirmar que os alunos e as alunas reconheceram os diferentes espaços e equipamentos de lazer do bairro Barreirinha, percebendo aqueles que permitem uma gama maior de possibilidades de vivências lúdicas no âmbito do lazer, seja observando, seja se apropriando dos mesmos.

Quando pensamos no objetivo de promover uma educação para o lazer por meio das aulas de Educação Física é possível afirmar que a maior parte dos alunos e alunas compreendeu a relevância do trabalho desenvolvido. Podemos evidenciar a importância dessa educação tanto nas apresentações dos resultados das observações quanto no questionário de avaliação da semana cultural.

Nesse momento, apresentamos algumas falas de alunos e alunas a respeito do trabalho desenvolvido. De acordo com uma aluna do $2^{\circ}$ ano A:

"A semana cultural foi muito boa, pois envolveu cultura, aprendizagem e um pouco de brincadeira na qual todos se divertiram e aprenderam alguma coisa". 
Nessa mesma direção dois alunos do $2^{\circ}$ ano D afirmaram que:

"A semana cultural foi excelente, todos os meios usados foram criativos e chamaram atenção para que todos participassem".

"Gostei da semana cultural porque foi dinâmica e tinha coisas legais para responder sobre o autor".

Sabemos que esse posicionamento por parte do corpo discente não ocorre em sua totalidade. No entanto, nossa função enquanto professores e professoras preocupados(as) com a educação dos(as) mesmos(as) deve estar sempre voltada para uma formação na qual os indivíduos vivam o tempo e o espaço de lazer de maneira positiva, sendo instrumentalizados para compreender a importância de manter em boas condições os diferentes equipamentos e propondo ações que permitam a comunidade se perceber como corresponsável pelos espaços. Nessa proposta, a escola como um todo tem papel central no processo de educar para o lazer, principalmente se nossa preocupação é contribuir para a emancipação dos indivíduos, favorecendo atitudes que permitam modificar as relações que se desenvolvem no plano social.

Na tentativa de atingirmos o último objetivo proposto no trabalho, quando pretendíamos reforçar a importância do diálogo com as outras disciplinas ao trabalhar com determinados conceitos, fica evidente, a partir das atividades apresentadas no decorrer do evento e por meio da análise das avaliações, que os alunos e as alunas compreenderam a magnitude do conceito de espaço apresentado nas aulas de Educação Física e Geografia, como descreveu uma aluna do $2^{\circ}$ ano B:

"Pesquisar sobre o autor foi agradável, pois achei interessante e ele fez grandes obras".

E um aluno do $2^{\circ} \mathrm{D}$ :

"O autor foi uma pessoa importante e com a pesquisa foi possível conhecer um pouco mais sobre ele e sua obra".

Se referindo à produção bibliográfica de Milton Santos, a qual teve maior repercussão fora do país - mesmo que atualmente vários grupos de pesquisa vêm se aprofundando em seus conceitos - os alunos do $2^{\circ}$ ano C relataram que:
"Foi bom estudar porque aqui no Brasil quase ninguém conhecia ele".

"Foi bom estudar sobre Milton Santos, mas não foi tão fácil, pois ele não é tão reconhecido no Brasil".

Trabalhar na escola com projetos que procurem valorizar o corpo discente, independentemente da idade, nos dá a possibilidade de ampliar o leque de opções para além do tempo e espaço escolar, desenvolvendo assim, a educação para o lazer. De um modo geral, admitimos que ao concluir essa proposta, conseguimos oportunizar momentos de cooperação, respeito e crescimento, principalmente, para os alunos e alunas do Colégio Estadual Gelvira Corrêa Pacheco.

A partir do desenvolvimento da Semana Cultural, do envolvimento da escola como um todo e da avaliação de todo o processo realizado, é possível afirmarmos que esse evento se concretizou como uma das possibilidades de educar nossos alunos e alunas para o lazer. A escola é um espaço que deve aproveitar todo o conhecimento desenvolvido, dentro ou fora dela, para qualificar a formação de seu corpo docente e discente, permitindo que ambos se modifiquem e se transformem.

Finalizando o debate teórico travado neste trabalho, procuramos enfatizar a importância da construção do saber escolar para a formação humana e profissional dos alunos e alunas, em contrapartida ao ensino tradicional, o qual geralmente deixa de lado a relevância social e cultural do fenômeno lazer. Isso significa dizer que o papel dos professores e professoras é proporcionar a maior gama de conhecimentos construídos historicamente pela humanidade, levando em consideração que o processo educativo torna-se nesta sociedade um campo de constantes conflitos e, como tal, representa interesses diversos.

\section{REFERÊNCIAS}

Camargo, L. O. L. (1998). Educação para o lazer. (3a ed.) São Paulo: Moderna.

Dumazedier, J. (1980). Valores e conteúdos culturais do Lazer. São Paulo: SESC.

Gasparin, J. L. (2002). Uma Didática para a Pedagogia Histórico-Crítica. (3a ed). Campinas, SP: Autores Associados.

Jacobs, J. (2003). Morte e vida de grandes cidades (Carlos S. Mendes Rosa). São Paulo: Martins Fontes. 
Japiassu, H., \& Marcondes, D. (1991). Dicionário básico de filosofia. (2a ed). Rio de Janeiro: Zahar.

Luckesi, C. C. (1986). Avaliação educacional escolar: para além do autoritarismo. In: Revista da educação AEC 15 (60), 23-27.

Marcellino, N. C. (1998). Lazer e educação. (8a ed). Campinas: Papirus.

Marcellino, N. C. (2002a). Estudos do lazer: uma introdução. (3a ed). Campinas: Autores Associados.

Marcellino, N. C. (2002b). Lazer e humanização. (6a ed). Campinas: Papirus.

Mascarenhas, F. (2000). Tempo de trabalho e tempo livre: algumas reflexões a partir do marxismo contemporâneo. Revista Licere 3 (1), 72-89.

Mascarenhas, F. (2003). Lazer como prática de liberdade: uma proposta educativa para a juventude. Goiânia: UFG.

Mascarenhas, F. (2005). Lazer e Utopia: limites e possibilidades de ação política. Revista Movimento (3), 155-182.
Minayo, M. C. de S. (1994). Pesquisa social: teoria, método e criatividade. Petrópolis, RJ: Vozes.

Minayo, M. C. de S. (2000). O desafio do conhecimento: pesquisa qualitativa em saúde. São Paulo: Hucitec.

Minayo, M. C. de S., Assis S. G., Souza E. R. (2005). Avaliação por triangulação de métodos: abordagem de programas sociais. Rio de Janeiro: Editora Fiocruz.

Paraná. Secretaria de Estado da Educação. (2008). Diretrizes curriculares de educação física para a educação básica. Curitiba: SEED.

Parker, S. (1978) A sociologia do lazer (George Allen). Rio de Janeiro: Zahar.

Pistrak, M. (2000) Fundamentos da escola do trabalho. São Paulo: Expressão popular.

Requixa, R. (1977). O lazer no Brasil. São Paulo: Brasilense.

Santos, M. (1986). Pensando o Espaço do Homem. São Paulo: Hucitec.

Saviani, D. (2002). Escola e Democracia: teorias da educação, curvatura da vara, onze teses sobre educação e política. Campinas: Autores Associados. 